\title{
Financial Reporting Web Sites: What Users Want in Terms of Form and Content
}

\author{
Roger Debreceny. Nanyang Technological University. Singapore. \\ rogerd@netbox.com
}

Glen L. Gray. California State University at Northridge. Glen.gray@csun.edu

Theodore J. Mock. University of Southern California. tmock@sba2.usc.edu

\begin{abstract}
Web-based financial reporting varies widely. Our research had three objectives: (1) identify design attributes for Web-based financial reporting; (2) rank those attributes; and (3) pilot test the Web as a survey tool.

Sixty-one attributes were developed from prior studies. The subjects were the subscribers of the "Double Entries" email newsletter. In terms of completeness, the respondents suggested seven additional attributes.

Regarding the second objective, some surprises were found. For example, the Jenkins Report emphasizes forward-looking information; yet, the respondents rated traditional content higher than forward-looking information. Traditional static attributes were rated higher than dynamic attributes.
\end{abstract}

In terms of presentation, the respondents were moderately adverse to downloading files, gave relatively low ratings to "bells and whistles," preferred hyperlinks and other navigation aids such tables of content over search and query functions.

Regarding the third objective, the response rate was $13.2 \%$, which was at the low end of response rates reported by similar projects.

Keywords: Financial reporting, Web design attributes, Web surveys 


\section{INTRODUCTION}

The Internet and, in particular, the World Wide Web (the $\mathrm{Web}^{1}$ ), are changing fundamentally the reach, timing and economics of the dissemination of financial and other corporate performance information. The Web provides an opportunity for the "mass-customization" 2 of information in a manner that is impossible with printed documents. For example, incorporating hypertext in Web-based financial reports allows document designers and users to create an unlimited number of independent contexts or perspectives over the same hypertext network, each constructed for a different category of users. This freedom comes from the ability of content to be presented in a variety of document maps, through appropriate use of hypertext (Conklin 1987; McAleese 1990; Klemme, Maurer, and Schneider 1996). In this way, both novice and expert users can selectively review the same body of material, freeing document designers from the task of tailoring the material for different audiences.

In addition to providing a new mode of information dissemination, the Web represents a totally new reporting environment. However, companies that want to move their financial and business performance information to the Web face many challenges. This paper addresses one critical issue: what attributes do end-users of financial-reporting Web sites consider most important? In this context, "attributes" refers to both the content elements and the forms of presentation.

This issue is set against a backdrop of widespread corporate use of the Web for investor relations. Corporations have rapidly adopted the Web for communicating with investors and other stakeholders. A recent Financial Accounting Standards Board (FASB) report (FASB 2000) reported that $99 \%$ of the top 100 companies in the 1998 Fortune 500 companies have Web sites, and, of those, 94\% include some form of financial reporting information (see also Ashbaugh, Johnstone, and Warfield 1999). Both of these numbers, particularly the second number are significantly higher compared to earlier studies that analyzed the 1996 and 1997 top 100 Fortune 500 companies (e.g. Gray and Debreceny 1997).

\footnotetext{
1 In this study, we refer to "the Web" as shorthand for all forms of Internet-based communication. The Web is the most important of the various protocols used in corporate performance reporting on the Internet.

2 Mass customization combines volume production of goods and services with the ability to customize those goods and services for individual customer needs (Pine 1993; Shapiro and Varian 1998).
} 
Smaller companies are also getting more involved with electronic reporting. A recent analysis of 370 companies randomly selected from the 10,000 listed companies on the New York Stock Exchange (NYSE), NASDAQ, and the Toronto Stock Exchange (TSE) found that 69\% companies had Web sites and 35\% had some form of financial reporting (Trites 1999). Although the U.S. may be leading in the number of companies reporting financial information on the Web, the rest of the world is catching up. Other research indicates widespread adoption of the Web for corporate reporting in Europe (Pirchegger, Schader, and Wagenhofer 1999; Deller, Stubenrath, and Weber 1999). A recent report from the International Accounting Standards Committee (IASC) (Lymer et al. 1999), based on an analysis of 660 companies from 22 different stock exchanges, indicated that $84 \%$ had Web sites and $62 \%$ had financial information. All of the top 30 companies on the Canadian, German, Sweden, and U.S. stock exchanges had Web sites. At the low end, $52 \%$ of the top 30 companies in Chile had Web sites.

The rapid and widespread adoption of Web-based financial and business reporting has captured the interest of the accounting profession in several parts of the world. Organizations such as the FASB, Securities Exchange Commission (SEC), American Institute of CPAs (AICPA), CICA in Canada, Institute of Chartered Accountants in England and Wales (ICAEW), the Accounting Standards Board (ASB) in the UK, and the IASC internationally are all conducting research or sponsoring policy initiatives on Web-based reporting. Arguably, the most important of these initiatives is the long-term development by a global consortium led by the AICPA of a new XML-based financial reporting language, $\mathrm{XBRL}^{3}$.

As the supply of Web-based financial information increases, investor demand for Web-based financial reporting is also increasing. There are now many millions of individual investors throughout the world who use the Web to research corporations as well as to make direct equity investments on both local and foreign bourses. Professional investors and managers use the Web to supplement proprietary databases (AIMR 1998; Deller, Stubenrath, and Weber 1999; Lymer et al. 1999).

Although estimates of the number of companies using the Web for financial reporting show dramatic growth in recent years, the actual trend may be even steeper than reported. This potential under-reporting is caused by the difficulty of determining whether a corporation actually has a Web site and then, once having found a corporate Web site, establishing the existence of all the different information elements. In short, there is wide variation in the quality and design of corporate Web sites.

3 www.xbrl.org 
This variation is an indication of the dynamic nature of Web-based financial reporting. Although it may be inevitable and arguably desirable at this stage of the Web's evolution, the extreme variation creates a variety of problems:

- Companies experience uncertainty about what information to display (content) and how to display it (form of presentation);

- Users experience difficult finding Web sites and, once having located a Web site, may have even more difficulty locating the information they seek; and

- Regulators and standard-setters experience difficulty tracking, monitoring, comparing, and assessing Web-based financial reporting practices of the organizations within their purview; as a result, they also find it difficult to provide recommendations, standards, or "best practices."

All three groups (corporations, users and standard setters), then, would benefit from knowledge about the content and presentation attributes of Web-based financial information that best meets users' needs and goals. Such knowledge would help corporations develop effective Web sites, facilitate users' efforts to obtain the information they seek, and assist regulators and standard-setters in identifying "best practices." The greater level of standardization that would result from corporate use of such "best practices" would also enhance efforts to monitor and track Web-based financial reporting.

One approach to fulfilling these needs is to determine the kinds of financial information that users find most helpful or important and the kinds of Web-based presentations that are most effective for conveying this information. Such research requires a framework for assessing both content and presentation of Web-based financial information. It also requires data from a user population. This paper reports on an exploratory study that encompasses both of these tasks.

The first stage of this study was to identify the basic population of content and design attributes for Web-based financial reporting. The flexibility of the Web as a medium for corporate disclosure provides many choices for corporations as to which information to disclos. The data collection instrument used in the FASB study (FASB 2000) included over 300 different design and information attributes. There is the related issue of how to disclose this information.

No single Web site could or, arguably, should include all content attributes. Similarly, using all possible styles of hypertext disclosure methods would reduce user productivity in interacting with the financial reporting site. Due to both usability 
and limited resources, each company must select the attributes perceived to be most valuable or important. As such, in addition to identifying attributes, guidance is needed to help select between attributes, which leads to the second stage of the study was to rank the attributes identified in the first stage. Because Web-based financial reporting is a relatively new phenomenon, there is little empirical research on user preferences for various attributes. To begin exploring this issue, we employed a survey approach to the second stage of the research.

Surveys of individuals who use Web-based financial information pose several difficulties, including identifying appropriate samples and gearing survey questions to the level of sophistication of the users. Additionally, because such populations are widely dispersed, data collection by traditional means can be highly expensive. Thus, we chose to conduct a Web-based survey because we want Web-savvy respondents and, secondarily, we want to test the feasibility of Web-based surveys.

This paper, then, describes our framework of Web-based financial information attributes and results of a Web-based survey in which accounting professionals rated the importance of various attributes The remainder of the paper proceeds as follows: in Section 2, we address issues relating to the content attributes of information disclosures on corporate Web sites. In Section 3, we review the form attributes of the disclosures, with an emphasis of building an understanding of user productivity in the Web-based environment. Section 4 describes the design of the study and the development of the research instrument. In Section 5, the results of the study are analyzed. Finally, in Section 6 we draw the various threads together in a conclusion and an agenda for future research.

\section{INFORMATION CONTENT}

Communication by corporations of financial and other corporate performance data to stakeholders is a complex process of risk and information asymmetry reduction coupled with strategic information management. The efficacy of that process is dependent upon the needs of the stakeholder and of the interests of the management of the corporation. The nature of information consumers varies widely between, for example, investors and analysts on the one hand, and community and labor organizations on the other hand. Even within a single group of stakeholders, the need for different types of information differs depending on their decision models. For investors, for example, the AICPA's "Special Committee on Financial Reporting" (Jenkins' Committee) identified six different strategies adopted for 
equity valuation ranging from those investors who "apply a multiple to the company's current or projected earnings, cash flows, or adjusted reported equity" to those who attempt to "identify recent favorable or unfavorable developments that are not yet reflected in the market price" (AICPA 1994, Chapter 3).

For managers, there are incentives to voluntarily communicate information to stakeholders. Voluntary communication serves to reduce the information asymmetry between professional managers and stakeholders who typically do not have dayto-day information regarding the operational and strategic issues facing the corporation. The incentives arise from a need by managers to, for example, control the agency relationships with stakeholders, particularly, providers of long-term equity and debt funds (Watts 1977; Holmstrum 1979; Fama 1980).

While the relationship between corporations is both complex and subtle, there are some common factors that can be identified in the needs of primary stakeholders. The Jenkins Committee, for example, identified the following classes of information in which stakeholders are primarily interested:

1. Financial and non-financial data.

2. Management's analysis of financial and non-financial data.

3. Forward-looking information.

4. Information about management and shareholders.

5. Background about a company. (AICPA 1994, Chapter 3)

This set of reporting characteristics is consistent with those expressed by, for example, the Association for Investment Management and Research (AIMR) in its 1993 report, "Financial Reporting in the 1990's and Beyond" (AIMR 1993). As can be seen from the Jenkins Report, communication of performance data by corporations to investors and other stakeholders is not confined to the financial statements, but also incorporates other current and forward-looking information.

The Web is now an important information dissemination medium by which corporations communicate with stakeholders. The Web changes corporate communication to stakeholders in three primary ways. First, the Web provides the corporation with the ability to cost-effectively package information for stakeholders from sources within and outside the corporation and with different levels of aggregation and disaggregation in ways that satisfy alternative decision making perspectives of the various classes of users identified by the Jenkins Committee. Second, the Web allows users to interact with corporate databases in an interactive 
fashion that is not possible in a print-based environment ${ }^{4}$. Third, information is now available synchronously and globally.

Given these factors, and the range of possible disclosures that corporations can make, it is important to understand which of the many possible disclosures Web-savvy information consumers value. We addressed disclosures from their perspectives: (1) the financial statements, (2) corporate background and news, and (3) forecasts. We briefly consider each in turn below:

Financial statements: Corporate financial statements are at the center of business reporting. Acting as a model to capture and organize financial information, financial statements package information in a structured manner that permits analysis of a wide range of trends and relationships. Investors use financial statements for various purposes such as a management performance evaluation, an early warning device, and an analytical tool.

Users differ in their sophistication, objectives, preferences and decision-making approaches. Consequently, different users demand different information (Elliott and Jacobson 1994; AICPA 1994). Analysts require investment, finance and strategic information. A casual reader, in contrast, may be more interested in the welfare and community activities of the company or the chairman's outlook of the industry or economy. Bouwman et al. (1995) examined the information usage of one major class of financial decision-makers-financial analysts-and found that even within the same group of users, the usage pattern of financial information is significantly different. Some financial analysts are more interested in descriptive information such as products, technology and management quality. Other analysts emphasized segment and prospective information.

Tailoring information interactively may satisfy the diverse information needs of users. Incorporating interactive technologies (i.e., hypertext) in the financial reports allow preparers of financial statements and users to create an unlimited number of independent perspectives over the same Web site. If the financial statement user requires only a limited amount of information from the annual report, it may be more practical to obtain that information from the Internet than to request a printed copy from the corporation.

\footnotetext{
4 Lymer et al. (1999) provide several case studies of corporations that have used the Web to make innovative disclosures or that have repackaged information in ways that enhance the user experience.
} 
Corporate background and news: Information published on a Web site is essentially immediately available from anywhere in the world at the same time. This contrasts with print-based information where information could take from a few minutes (e.g., a fax of a quarterly report), to many days for a mailed copy of a printed annual report. The AICPA's Special Committee on Financial Reporting (AICPA 1994) found that users wish to know about critical transactions and events as soon as possible. Speedy release of such information can be made through releases on the corporate Web sites (AIMR 1998). Further, the Web site can readily host complete archives of corporate press releases as well as in-depth background on products and services.

Forecasts: The Web provides a form of dissemination that can provide a flexible format to present forward-looking information. The recent Webcasting by a number of corporations of earnings calls and analysts briefings shows how the Web can provide a vehicle for forecasts. At the same time the Web can reduce some of the inherent risks to corporations in providing forecast information by, for example, making explicit use of safe-harbor provisions (Miller and Young 1997).

\subsection{Typology of Content}

There is no accepted typology of stakeholder information content. In building our typology, which is expressed in the survey instrument discussed below, we were guided by the reports of the Jenkins Committee and the AIMR, as well as by commentaries such as that provided by Wallman (1997). Arnold and Moizer (1984) ranked the degree of influence each type of information elements in a traditional printed annual report. We have adapted their study to provide users with a scale to rank the relative importance of financial information content available on corporate Web sites. At the same time, in addition to these studies, the typology was also developed based on observations of various features (or attributes) employed by corporations that have posted their financial reports on the Web. Web sites of corporations such as Microsoft, Intel, 3M and AT\&T, which have established a presence on the Web, were studied to ensure that possible key attribute were not omitted.

\section{INFORMATION FORM OF PRESENTATION}

\subsection{Introduction}

The Web provides a multimedia information dissemination channel. Elements of Web-based reporting are, of course, familiar. Text, numeric data and graphics 
are similar to that presented in printed reports, albeit with radically different navigation strategies. Video, audio and direct interaction with corporate databases is, however, entirely new to business reporting. We can see a migration of reporting from forms of presentation closely related to print-based dissemination to forms of presentation that take advantages of underlying Web technologies. This migration of the form of information presentation presents many new issues in humancomputer interaction (HCI).

While a full exploration of these issues is beyond the scope of this paper ${ }^{5}$, we address these issues of HCI from three perspectives: (1) the overall accessibility of the corporate Web site, (2) the design and functionality of individual Web pages and other site design features, and (3) the hypertext navigation strategies adopted for the site.

\subsection{Site Accessibility}

Issues such as overall access to the Web site and the tools that are necessary to use the site are important to consider. How much of an impediment is, for example, the need to download Adobe Acrobat to read financial statements in Adobe's PDF format? Does the requirement to register on a site negatively impact on user perceptions of the site? PDF files may improve off-line printing and having users register may help corporations track who is visiting their Web sites, but research must explore the trade-offs from the users' perspectives.

\subsection{Web Page Functionality and Design}

In this section we address issues of the usability of individual Web pages within the financial reporting Web site. For example, Nielsen (1997) argues that excessive use of graphics impact negatively upon the user experience. While the major Web browsers allow users to turn off graphics to save downloading time, a text-based alternative should, Nielsen argues, always be provided in addition to a graphical interface. However, as this study explores, is Nielsen's view supported by end-users perception of the use of multimedia on corporate financial reporting sites?

5 See Driscoll et al. 1999, 2000 for a fuller exploration of some of these issues. 
Another design question is how important to end-users is the currency of information on the site and notification of the date on which Web pages were changed? By presenting financial statements on the Web, corporations are able to provide more timely information by frequently updating their Web sites. The AICPA (1994) asserts that critical events should be reported within a few days of occurrence. Speedy release of critical information could be made through press releases on the corporate Web sites (AIMR 1998).

\subsection{Hypertext and Navigation Design Strategies}

Hypertext systems allow information users to create, annotate, link together, and share information (Nielsen 1990). The hyperlink, which allows arbitrary movement from resource to resource, is the foundation for hypertext (Shneiderman and Kearsley 1989). A variety of media such as text, graphics, audio, video, animation, and programs are used within hypertext 'pages'. Together, the hyperlink and multimedia provide a different method of accessing information, which can be sequential or non-sequential. This is unlike traditional print-based media, which are primarily sequential in nature. In summary, hypertext provides flexible access to information by incorporating the notions of navigation, annotation, and tailored presentation (Bieber and Isakowitz 1995). However, as explained below, hypertext can introduce disorientation and cognitive overload.

Disorientation: The problem of disorientation or "getting lost in hyperspace" arises from the need to know where one is in the network of hyperlinks, where one came from, and how to get to another place in the network (Dillon, McKnight, and Richardson 1990). In traditional text, it is not easy for the reader to get lost. The information is arranged in a linear fashion. There are usually the table of contents of topics with page numbers, the index with keywords, and page numbers. However, in a complex hypertext network, with hundreds or thousands of nodes and links, it is more than likely that the reader will get lost.

Cognitive Overload: Cognitive overload can happen to readers of hypertext systems. The overload may arise from the need for the user to make decisions as to which links to follow and which to abandon, when given a large number of choices. The process of pausing (either to jot down required information or to decide which way to go) can be very distracting. It can become a serious problem if there are a large number of nodes and links (Balasubramanian 1994). The simplicity and consistency of the hypertext structure help in reducing the load on the user. It also reduces the learning time necessary to reach a sufficient level of knowledge of the hypertext (Agosti and Smeaton 1996). This is a concern when 
companies post their financial reports on the Web. On the one hand, corporations may desire to create a comprehensive site so that sophisticated information consumers, such as investment analysts, may gather sufficient information for their decision models. However, this may overload the average investor who just requires some basic information.

There are several possible solutions to these potential problems including graphical browsers, overview diagrams, Web views, paths, trails, history lists, backtracks, queries, and roam and zoom techniques (Balasubramanian 1994). Authoring guidelines have also been proposed for the organization of information in a hypertext system (Nielsen 1990; 1999).

\subsection{Conclusion}

There has been no systematic and comprehensive approach towards the design of $\mathrm{HCI}$ for multimedia and hypertext systems relating to financial reports. Yet, many corporations have spent considerable sums on constructing corporate Web sites. We were interested, then, in the perception of end-users to multimedia and hypertext HCI attributes. The HCI literature was used to build a framework for understanding the form attributes and related issues, when end-users interact with a corporate reporting Web site.

\section{RESEARCH METHODOLOGY AND DATA COLLECTION}

\subsection{Research Instrument}

An extensive literature search revealed a lack of existing research instruments to address either the issues of information content or form attributes. Since there has been little research carried out on this specific topic, the resulting research instrument draws upon prior research conducted in accounting, hypertext, readability, and the use of graphs and presentation of information. Studies such as those conducted by Arnold and Moizer (1984) (information content) and Bouwman et al. (1987) and Dillon et al. (1990) (information form) were integral to the development of this instrument. The study conducted by Bennett et al. (1997) provided a comprehensive list of attributes on the assessment of Internet resource quality. Attributes raised by Bennett et al. (1997) include the presence of email interaction on the site, the ability to download the financial statements, site registration, and site interactivity. 
Using the studies mentioned in the literature review and the sources above, questions were formulated to address Web financial reporting attributes. The instrument is primarily a Likert-scale instrument consisting of 61 items that present both positively and negatively worded statements on the attributes of financial reporting on the Web. For each attribute, respondents selected one of five responses. Depending on the way the question has been phrased, the scale ranges from Not important at all to Very Important, Strongly disagree to Strongly agree and Not at all to Certainly. Due to the exploratory nature of the study and the quest for previously unknown factors, six free response items were included. They were included to facilitate the identification of omitted attributes or other factors.

The instrument was pre-tested on groups of senior students and on a range of faculty that were familiar with either or both accounting and usability issues. The final instrument is reproduced in the Appendix.

\subsection{Distribution of questionnaire}

Email and Web-based forms are now increasingly used for survey research (Smith 1997; Coomber 1997; Selwyn and Robson 1998; Stanton 1998). Email surveys are typically undertaken by emailing the survey instrument to the respondent, asking them to complete the survey and to reply by email.

Web-based surveys use a Web form that captures the responses and writes the response to a file or database. The Web form may be tailored to react to particular responses by branching. Respondents are sought by email, postings to newsgroups or by links from Web pages. One of the largest Web-based surveys ${ }^{6}$, the Georgia Tech survey of the Web, uses the latter two methods to seek respondents to their long-established survey (Kehoe and Pitkow 1996).

Schillewaert (1998, p 309) describes the advantages and disadvantages of Webbased surveys. Advantages include low cost, rapid responses from those surveyed, user convenience and the ability to provide explanations to respondents on the meaning of particular questions. Disadvantages include the limited pool of potential respondents (they must use the Internet regularly in order to be contacted to complete the survey and then to go on to complete the survey), absence of population lists and the concern that others than those contacted may be completing the survey.

\footnotetext{
6 The latest reported survey (December 1998) had more than 5,000 respondents. See: http:// www.gvu.gatech.edu/gvu/user_surveys/survey-1998-10/
} 
Few of these disadvantages applied in this study. Given that this study was about the use of the Web and financial and corporate reporting we actively sought out a Web-savvy population. The subscriber list of "Double Entries," which is a weekly email newsletter that covers developments in accounting and auditing, was made available to the researchers. It was considered that subscribers to this list would be both knowledgeable about accounting and the Web. By being on the subscription list, the subscribers have shown that they use the Web. The residual concern with the survey was that others than those contacted by email could complete the survey. The advantages of global distribution of knowledgeable respondents, high quality and low error rate of responses and ease of capturing the response data outweighed any residual concerns.

\section{RESULTS}

\subsection{Response Rate}

Email requests to complete the questionnaire were sent to the 1,438 email addresses on the mailing list. There were 163 invalid email addresses from the mailing list, reducing the sample population to 1,275 . The duration of the data collection period was six weeks. The first reminder was sent one week after the initial request. The second was sent a week later. The third and final reminder was sent on the fifth week of the data collection period.

The total number of responses received was 173 - an initial response rate of $13.6 \%$. Of these, two were rejected due to incomplete data and another two were duplicate entries. The exclusion of these invalid questionnaires provided a sample of 169 , giving a final response rate of $13.2 \%$. This response rate is reasonable as compared with published email and Web-based surveys. Responses in these studies have ranged from a low of 6\% (Tse et al. 1995), to $13.5 \%$ in a survey that employed financial incentives (Comley 1996) to $24 \%$ for a large-scale (5,000 names) email survey (Sheehan and Hoy 1999) and 36\% for the small-scale survey conducted by Schillewaert et al. (1998).

A primary concern of low response rates is potential non-response bias (Ratneshwar and Stewart 1989). A variety of tests were conducted on the serial receipt of responses. There was no evidence of serial order bias.

\subsection{Profile of Respondents}

Of the 169 respondents, $71 \%$ are males. The age of the respondents range from twenty to sixty-five years old. As expected, the respondents are almost 
exclusively from an accounting background. Some $99 \%$ of the respondents have a university degree with $82 \%$ having a post graduate degree. The median respondent had been using the Internet for four years.

Respondents were drawn from 21 countries, with the USA (36\%), Australia (30\%) and New Zealand (7\%) accounting for the majority of the responses. Respondents from the education/training industry form $58 \%$ of the responses while professional accountants represent the next largest segment, accounting for $23 \%$.

\subsection{Information Content}

Table 1 shows the desired information content attributes, ranked in descending order of mean values. The traditional elements of the financial statements, including the core financial statements, notes, auditors' report and annual report, are the most highly ranked information attributes

The presumption by the Jenkins Report that information consumers will desire forward-looking information content was not supported. Forward-looking information such as performance forecasts $\left(10^{\text {th }}\right.$ rank $)$, current acquisitions $\left(14^{\text {th }}\right.$ rank), vision statement ( $19^{\text {th }}$ rank) and background information such as press reports $\left(23^{\text {rd }}\right.$ rank) and customer ( $24^{\text {th }}$ rank) and employee profile $\left(25^{\text {th }}\right.$ rank) were not rated as highly as traditional content attributes by the participants in the study.

There was a high level of consistency in rating the information content attributes by the various types of respondents. Table 2 shows the ratings of information content attributes by employment type. Casual observation of Table 2, supported by Chi Square tests, demonstrates that there are no significant differences between the groups. There were no statistical differences on other dimensions such as respondents' qualifications, age or experience in using the Web.

We were interested to understand the attitudes of respondents to alternative ways in which they could tailor information on the Web. Table 3 shows possible customization, including currency conversions, "what-if" models and the availability of alternative accounting methods. The overall ratings did not approach the level of ratings for more traditional and static information attributes. For example, the rating shown for "what-if" models (mean 3.83) would have placed it at the $21^{\text {st }}$ position on the list of desired information attributes shown in Table 1.

Respondents were also asked to indicate any other information that should be provided. Their returns included human resource data, environmental health and safety reports, directories of staff, relevant industry events, details of credit facilities and pending litigation. 


\begin{tabular}{|c|c|c|c|}
\hline & \multicolumn{2}{|c|}{ Man } & \multirow{2}{*}{$\begin{array}{c}\text { Sal Deration } \\
\text { Setintic }\end{array}$} \\
\hline & Setintic & Sad Erar & \\
\hline Con Feasial Sthereis & $4 m$ & IfIS & 37 \\
\hline Awad Repart & $4 \times 2$ & 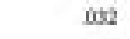 & 42 \\
\hline Notara & 4.79 & 081 & 54 \\
\hline Audiens Repoet & 464 & 084 & 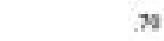 \\
\hline Sogearal & 4ss & bex & A2 \\
\hline Fin Surmary 2 yn & 434 & 057 & $n 2$ \\
\hline Monegenct Rapest & 431 & 067 & 6) \\
\hline Non-Tiandal Indeasen & 442 & 187 & 24 \\
\hline Fon Surnary 5 yn & 440 & 05 & .00 \\
\hline Funcasta & 437 & 082 & 67 \\
\hline Hation & 434 & $\cos$ & 75 \\
\hline Varanterisn & 4.32 & bes & a7 \\
\hline Marapanat Acpera & 4.32 & 681 & 60 \\
\hline Cancer acgisitions & 4.25 & 000 & 64 \\
\hline Druexers Requat & 4.23 & test & s3 \\
\hline Araly at llepert & 4.16 & $\operatorname{ten}$ & 30 \\
\hline Derestus ' Natea & 4.67 & .672 & 93 \\
\hline Slere Fieo Dus & 7.94 & OT4 & 95 \\
\hline Viee Stmonert & 3.91 & ont & $\mathbf{w}$ \\
\hline Than Releasa & 3.34 & tote & is \\
\hline Bearamic forctant & 3.81 & .664 & 83 \\
\hline Dirasturs BedDun & 3.77 & $a n$ & 92 \\
\hline Press Repors & 3.34 & 964 & 83 \\
\hline Costraer Brofis & 373 & oss & 6 \\
\hline Enplave fmalk & 3.69 & ost & 10 \\
\hline
\end{tabular}

Table 1. Mean Ratings of Information Content Attributes

(Scale: 5 = highest and $1=$ lowest ratings)

\begin{tabular}{|c|c|c|c|c|}
\hline & \multicolumn{3}{|c|}{ Enployonese } & \multirow[t]{2}{*}{ Tata } \\
\hline & Acoderiant & $\begin{array}{c}\text { Elucations } \\
\text { Trumere }\end{array}$ & One: & \\
\hline Armal Repont & 4.9 & 4.9 & 4.7 & 4.8 \\
\hline Camings Releves & 4.5 & 4.5 & 49 & 4.9 \\
\hline Csmect oxpainitions & 43 & 42 & 4.4 & 4.2 \\
\hline Fucteats & 43 & 43 & as & 4.4 \\
\hline Masaperaest Seporta & 42 & 43 & 4.5 & 4.3 \\
\hline Fia Stmanury zyn & 4.4 & 46 & 4.5 & 4.9 \\
\hline Cart Fisuecix Srasemsws & 4.9 & 4.9 & 4.7 & 4.9 \\
\hline Netes & 48 & 4.9 & 45 & 4.8 \\
\hline Dirbodures' Ptepart & 4.3 & 42 & 42 & 42 \\
\hline Segrneatal: & 46 & 4 a & 4.4 & 4.6 \\
\hline Ranise & 4.3 & 43 & 4.4 & 43 \\
\hline Non-Fiasaciv ladersos & 44 & 44 & 44 & 44 \\
\hline
\end{tabular}

Table 2. Selected Information Content Attributes by Employment Type 


\begin{tabular}{|l|cr|r|}
\hline \hline & \multicolumn{2}{|c|}{ Mean } & Std. Deviation \\
\cline { 2 - 4 } & Statistic & Sid. Error & \multicolumn{1}{c|}{ Statistic } \\
\hline Links to notes & 4.45 & .052 & .67 \\
What-if model & 3.83 & .067 & .87 \\
Accounting method & 3.82 & .088 & 1.13 \\
Custumised reports & 3.75 & .076 & .97 \\
Country conversion & 3.67 & .079 & 1.01 \\
Currescy conversion & 3.02 & .072 & .93 \\
\hline \hline
\end{tabular}

Table 3. Financial Reporting Customization. (Scale: $5=$ highest and $1=$ lowest ratings)

\subsection{Information Form of Presentation}

Recall that the foci of the study with respect to the form of information on corporate Web sites was on site access and usability, Web page design and site functionality, and site navigation and design. The results on each of these aspects of form are now considered in turn.

Site access and usability: It is common for financial reporting sites to require users to download Adobe Acrobat to read financial reporting documents and some require the user to register on the site. Table 4 shows the attitude of respondents to these issues. Clearly, download time is a concern of respondents. In addition, the respondents are moderately averse to using Adobe Acrobat as can be seen from their responses to the question "I prefer not to download software (e.g. Adobe Acrobat) in order to read financial statements" (Mean 3.361 = Strongly disagree, $5=$ Strongly agree) .

\begin{tabular}{|c|c|c|c|}
\hline & \multicolumn{2}{|c|}{ Mean } & Std. \\
\hline & Statistic & Std, Errar & $\begin{array}{l}\text { Deviation } \\
\text { Statistoc }\end{array}$ \\
\hline Time taken ta download & 4.06 & 060 & 78 \\
\hline Site logon & 3.76 & 079 & 1.02 \\
\hline Download required & 3.36 & .096 & 124 \\
\hline PDF preferred & 3.33 & .086 & 1.11 \\
\hline
\end{tabular}

Table 4. Site Access and Usability Attributes

(Scale: 5 = highest and $1=$ lowest ratings)

Web page design and site functionality: The issues in this section related to common functionality of the Web site. We asked respondents to give rankings for "enhanced" features of Web sites, including discussion lists and language conversion. Reflecting the essentially temporal nature of accounting information, 
as shown in Table 5, the respondents strongly rated the presentation of modification and release dates on individual pages.

Table 6 shows there were relatively weak ratings for features such as email links on the Web site. Further, there were only minor ratings for "bells and whistles". When asked how they valued multimedia in the context of the Chairman's Report, some $56 \%$ of the respondents said that these features were of "no value".

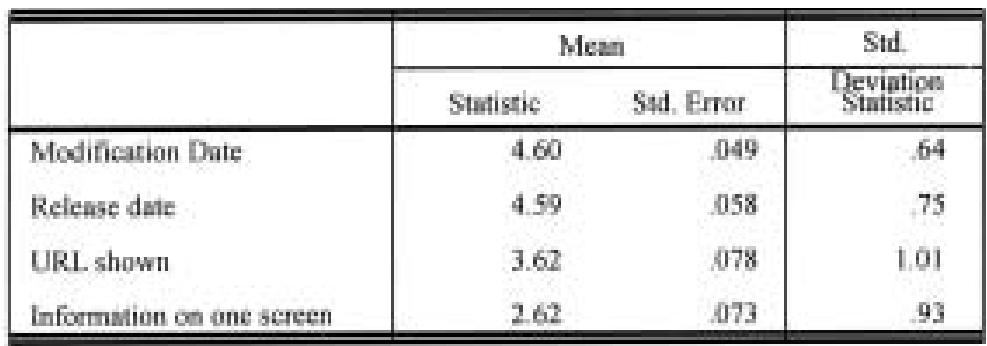

Table 5. Web Page Design Functionality Attributes

\begin{tabular}{|c|c|c|c|}
\hline & \multicolumn{2}{|c|}{ Mean } & \multirow{2}{*}{$\begin{array}{c}\text { Sod. } \\
\text { Stativise }\end{array}$} \\
\hline & Suatatie & Sal Enar & \\
\hline Grapls. & 3.75 & .060 & 8.03 \\
\hline Emall links & 3.31 & 096 & 1.24 \\
\hline Testronly & 3.07 & .096 & 1.23 \\
\hline History List & 297 & coss & 1.11 \\
\hline Descussion Itsx & 207 & डबा & 1.11 \\
\hline Laryingt eonversios & 2.16 & 092 & 1.18 \\
\hline
\end{tabular}

Table 6. Web Page Design Enhanced Features

Site navigation and design: It has been suggested that search and query tools need to be elevated to a primary mechanism on par with navigation. However, this study revealed that the respondents do not view search and query functions to be as important as navigational aids. Table 7 shows the desired navigation and hyperlink attributes, in descending rank order. Navigation tools such as site maps, tables of contents, consistent navigation strategies and indexes on each page in the Web site are all highly rated as compared with availability of built-in search, help systems and annotation links or color coding of pages. There was essentially no difference in responses to issues of navigation and hyperlink management set out in Table 7 by any of the dimensions of respondents such as length of time using the Internet, age or employment type. In essence, the Web design strategies promulgated by, for example, Jakob Nielsen ${ }^{7}$, are supported by the results of this study.

7 See Nielsen 1990 and http://www.useit.com/ 


\begin{tabular}{|l|rr|r|}
\hline \hline & \multicolumn{2}{|c|}{ Mean } & \multicolumn{1}{c|}{ Std. } \\
\cline { 2 - 4 } & Statistic & Std. Error & $\begin{array}{c}\text { Deviation } \\
\text { Statistic }\end{array}$ \\
\hline Site map & 4.67 & .041 & .52 \\
Table of Contents & 4.57 & .045 & .58 \\
Navigation consistency & 4.27 & .048 & .61 \\
Link to Fin Reptg Home Page & 4.05 & .054 & .69 \\
Index on each page & 4.00 & .064 & .82 \\
Built-in search & 4.00 & .060 & .77 \\
Elaboration on link & 3.93 & .051 & .66 \\
Link to corporate home page & 3.87 & .059 & .76 \\
Help availability & 3.54 & .073 & .95 \\
Color coding & 3.46 & .070 & .91 \\
Annotation links & 3.31 & .078 & 1.01 \\
Frames & 3.21 & .078 & 1.00 \\
\hline \hline
\end{tabular}

Table 7. Navigation and Hyperlink Attributes

\section{CONCLUSIONS}

A first objective of this study was to identify content and form attributes. In terms of the 61 attributes used in this study we seemed to achieve our basic objective. Out of the 169 respondents, the only attributes suggested included: human resource data, environmental health and safety reports, directories of staff, relevant industry events, details of credit facilities, and pending litigation. Presumably, adding these six attributes to our existing list would result in a very robust list of design attributes that could be subsequently used to evaluate financial reporting Web sites.

A second objective of this study was rank the attributes. The analysis did find some surprises. For example, the Jenkins Report emphasizes forward-looking information, yet, our respondents rated traditional content elements higher than forward-looking information. In addition, this response was consistent over different demographics within our respondents. In terms of dynamic attributes (e.g., "whatif") vs. static attributes (e.g., traditional financial statements), the respondents ranked the static attributes higher than the dynamic attributes. 
In terms of the attributes related to the form of presentation, the respondents were moderately adverse to the need to download files (e.g., downloading the Adobe Acrobat Reader). In addition, the respondents gave relatively low ratings to "bells and whistles" such as email links on the Web site. In terms of navigation, the respondents liked hyperlinks and other navigation aids such tables of content over search and query functions.

In general, this study indicates that financial reporting Web sites should primarily present information in text and graphical format. Use of multimedia such as audio and video clips are of secondary importance. A good overview or sitemap, which allows the reader to quickly find a particular topic, is valuable. Users would also like a Table of Contents to navigate within the Web site. A hypertext system of information, such as the electronic financial statements, provides users with the ability to aggregate disaggregated data. This study reveals that users are satisfied with the content and presentation of information traditionally included in financial reports. They would prefer not to customize reports, choosing instead to rely on conventional reports. However, in the future, as the Web grows in popularity and users gain greater ease in the use of Internet, it will be interesting to see if more users will tailor or customize financial statements to their specific needs.

While the results provide some interesting insights into users' perception of a high quality financial reporting Web site, the results must be interpreted in the light of the limitations of the study. Firstly, certain limitations inherent in survey methods of collecting data should be kept in mind. Not all subscribers of "Double Entries" who received the questionnaire responded to it. There is a potential nonresponse bias in that non-respondents may systematically differ from the respondents in ways that could affect the study's findings.

Secondly, the composition of the sample population is restricted to a particular class of users. The email was sent to the recipients of the mailing list, Double Entries, which consisted of mainly accounting professionals and academics. These recipients represent only one of many classes of users of financial statements, such as financial analysts, investors, employees and many others. The results may not be representative of a wide user population.

Finally, due to the turbulence and the rapid growth of Internet and related technology such as hypertext, answers provided by the respondents may only reflect their own opinions at a point in time. Because of the rapid changes in Internet 
technology, it is possible that such opinions may also quickly change. In other words, a only cross-sectional study was feasible, not a longitudinal study.

This study has provided a preliminary study of quality attributes for financial reporting Web sites that can provide a basis for future research. For example, future research could involve a wider sample population, such as financial analysts, investors and all other interested parties. In this exploratory study, our focus was narrow and only accountants and academics were surveyed. Further analytical, theoretical and empirical work is necessary to enhance generalization of the results. In addition, future research could examine other forms of disclosures other than annual reports. Very little research has been done in these areas. It would also be interesting to study the possibility of replacing printed annual reports with electronic reports. A printed annual report may soon become a rarity. Finally, studies could be conducted to evaluate Web sites, using the expanded list of attributes identified in this study.

\section{REFERENCES}

Agosti, M, and A Smeaton, eds. (1996): Information Retrieval and Hypertext. Boston: Kluwer.

AICPA. (1994): Report of the Special Committee on Financial Reporting: Improving Business Reporting - A Customer Focus: Meeting the Information Needs of Investors and Creditors. New York, NY: American Institute of Certified Public Accountants.

AIMR. (1993): Financial Reporting in the 1990's and Beyond. New York: Association for Investment Management and Research.

AIMR. (1998): Using Technology and the Internet: Researching Corporate and Strategic and Financial Information. New York: Association for Investment Management and Research.

Arnold, J, and P Moizer. (1984): A survey of the methods used by UK investment analysts to appraise investments in ordinary shares. Accounting and Business Research 14 (55):195-207.

Ashbaugh, H, KM Johnstone, and TD Warfield. (1999): Corporate Reporting on the Internet. Accounting Horizons 13 (3):241-257.

Balasubramanian, V. (1998): State of the Art Review on Hypermedia Issues And Applications [URL]. Rutgers University, March 30, 19941994 [cited December 1998]. Available from http://cbl.leeds.ac.uk/nikos/doc/maps/maps.html. 
Bennett, LT, KM Oliver, and GL Wilkinson. (1997): Evaluating the Quality of Internet Information Sources: Quality Indicators as Ranked by Experienced Users.

Bieber, M, and T Isakowitz. (1995): Designing hypermedia applications. Communications of the ACM 38 (8):26-29.

Bouwman, MJ, P Frishkoff, and PA Frishkoff. (1995): The relevance of GAAPbased information: A case study exploring some uses and limitations. Accounting Horizons 9 (4):22-47.

Bouwman, MJ, PA Frishkoff, and P Frishkoff. (1987): How Do Financial Analysts Make Decisions? A Process Model of the Investment Screening Decision. Accounting, Organizations and Society 12 (1):1-29.

Comley, P. (1999): The Use of the Internet as a Data Collection Method. Virtual Surveys Limited 1996 [cited August, 20 1999]. Available from http:// www.virtualsurveys.com/papers/email.htm.

Conklin, J. (1987): Hypertext: An introduction and survey. IEEE Computer 20:17-41.

Coomber, R. (1997): Using the Internet for Social Research. Sociological Research Online 2 (2).

Deller, D, M Stubenrath, and C Weber. (1999): A Survey of the Use of the Internet for Investor Relations in the USA, UK and Germany. European Accounting Review 8 (2):351-364.

Dillon, A, C McKnight, and J Richardson. (1990): Navigation in hypertext: a critical review of concept. In Human-Computer Interaction - INTERACT '90, edited by D Diaper. Amsterdam: Elsevier.

Driscoll, D, J Arney, R Debreceny, and G Gray. (1999): Designing the Next Generation of Financial Reporting Web Sites. Paper read at 11th Asian-Pacific Conference on International Accounting Issues, at Melbourne, Australia.

Driscoll, D, J Arney, R Debreceny, and G Gray. (2000): The Complexity of WebBased Financial Communications: A Multidimensional Perspective. Paper read at American Accounting Association Annual Meeting, at Philadelphia.

Elliott, RK, and PD Jacobson. (1994):. Costs and benefits of business information disclosure. Accounting Horizons 8 (4):80-96.

Fama, E. (1980): Agency Problems and the Theory of the Firm. Journal of Political Economy:288-307.

FASB. 2000. Business Reporting Research Project: Electronic Distribution of Business Information. Norwalk, CT: Financial Accounting Standards Board. 
Gray, GL, and RS Debreceny. (1997): Corporate Reporting on the Internet: Opportunities and Challenges. Paper read at Seventh Asian-Pacific Conference on International Accounting Issues, November, at Bangkok.

Holmstrum, B. 1979. Moral hazard and observability. Bell Journal of Economics 15 (Spring):74-91.

Kehoe, CM, and JE Pitkow. (1996): Surveying the Territory: GVU's Five WWW User Surveys. The World Wide Web Journal 1 (3):77-84.

Klemme, M, H Maurer, and A Schneider. (1996): Glimpses at the future of networked hypermedia systems. Journal of Educational Multimedia and Hypermedia 5 (3-4):225-238.

Lymer, A, R Debreceny, G Gray, and A Rahman. (1999): Business Reporting on the Internet. London: International Accounting Standards Committee.

McAleese, R. (1990): Navigation and Browsing in Hypertext. In Hypertext: State of the Art, edited by R McAleese. Oxford: Intellect.

Miller, R, and MR Young. (1997): Financial Reporting and Risk Management in the 21st Century. Fordham Law Review 65 (5):1987-2064.

Nielsen, J. (1990): Multimedia and Hypertext, The Internet and Beyond. SunSoft: Mountain View.

Nielsen, J. (1999): How Users Read on the Web [URL]. useit.com 1997 [cited 11 August 1999].

Nielsen, J. (1999): “Top Ten Mistakes” Revisited Three Years Later [URL]. http:/ /www.useit.com/altertbox/990502.html, May 2, 19991999 [cited 8 August 1999 1999].

Pine, BJ. (1993): Mass customization: The new frontier in business competition. Boston, Mass.: Harvard Business School Press.

Pirchegger, B, H Schader, and A Wagenhofer. (1999): Financial Information on the Internet - A Survey of the Homepages of Austrian Companies. European Accounting Review 12.

Ratneshwar, S, and D Stewart. (1989): Non-response in mail surveys. Applied Marketing Research 29 (3):37-46.

Schillewaert, N, F Langerak, and T Duhamel. (1998): Non-probability sampling for WWW surveys: A comparison of methods. Journal of the Market Research Society 40 (4):307-322.

Selwyn, N, and K Robson. (1998): Using e-mail as a research tool. Social Research Update. 
Shapiro, C, and H Varian. (1998): Information Rules: A Strategic Guide to the Network Economy. Cambridge, Mass: Harvard Business School Press.

Sheehan, KB, and MG Hoy. (1999): Using E-Mail to Study Internet Users in the United States: Methodology and Assessment. Journal of Computer Mediated Communication 4 (3).

Shneiderman, B, and G Kearsley. (1989): Hypertext hands-on! : an introduction to a new way of organizing and accessing information. Reading, Mass.: AddisonWesley.

Smith, CB. (1997): Casting the Net: Surveying an Internet Population. Journal of Computer Mediated Communication 3 (1).

Stanton, JM. (1998): An empirical assessment of data collection using the Internet. Personnel Psychology 51:709-725.

Trites, G. (1999): The Impact of Technology on Financial and Business Reporting. Toronto: Canadian Institute of Chartered Accountants.

Tse, A, Smith, Jones, Brown, Smith, and Wong. (1995): Comparing two methods of sending out questionnaires: email versus mail. Journal of the Market Research Society 37 (4):441-446.

Wallman, SMH. (1997): The future of accounting and financial reporting Part IV: Access Accounting. Accounting Horizons 11 (2):103-116.

Watts, RL. (1977): Corporate Financial Statements, A Product of the Market and Political Process. Australian Journal of Management 2:53-75. 